Western University

Scholarship@Western

Paediatrics Publications

Paediatrics Department

2017

Cytoplasmic Distribution of HIV-1 Tat Sensitizes

Jurkat T Cells to SulphamethoxazoleHydroxylamine Induced Toxicity

Kemi Adeyanju

Robarts Research Institute

Gregory A. Dekaban

Western University

Michael J. Rieder

Western University

Follow this and additional works at: https://ir.lib.uwo.ca/paedpub

Part of the Pediatrics Commons

Citation of this paper:

Adeyanju, Kemi; Dekaban, Gregory A.; and Rieder, Michael J., "Cytoplasmic Distribution of HIV-1 Tat Sensitizes Jurkat T Cells to Sulphamethoxazole-Hydroxylamine Induced Toxicity" (2017). Paediatrics Publications. 108.

https://ir.lib.uwo.ca/paedpub/108 


\title{
Cytoplasmic Distribution of HIV-1 Tat Sensitizes Jurkat T cells to Sulphamethoxazole-Hydroxylamine Induced Toxicity
}

\section{Kemi Adeyanju ${ }^{1,2}$, Gregory A. Dekaban ${ }^{1,2^{\star}}$ and Michael J. Rieder ${ }^{1,3}$}

${ }^{1}$ Biotherapeutics Research Laboratory, Molecular Medicine, Robarts Research Institute, London, Ontario, Canada

${ }^{2}$ Department of Microbiology \& Immunology, Schulich School of Medicine \& Dentistry, University of Western Ontario, London, Ontario, Canada

${ }^{3}$ Department of Pediatrics and Physiology \& Pharmacology, Schulich School of Medicine \& Dentistry, University of Western Ontario, London, Ontario, Canada

\begin{abstract}
Background: One medication commonly used by HIV-1-infected individuals is the antimicrobial sulphamethoxazole (SMX), which is used in the treatment and prophylaxis of pneumocystis pneumonia. However, SMX is responsible for a very high incidence of hypersensitivity adverse drug reactions (ADRs) in the HIV-1 population. While the pathophysiology of ADRs in general is unknown, sulphamethoxazole-mediated ADRs have been linked to its reactive metabolite sulphamethoxazole-hydroxylamine (SMX-HA). Our previous work has shown that increased expression of the HIV-1 Tat protein in T cells correlated with increased apoptosis after incubation with SMX-HA. In this study we sought to determine the region of the Tat protein responsible for this effect and the mechanism by which Tat contributed to SMX-HA mediated apoptosis.
\end{abstract}

Methods: We established Jurkat T and Cos 7 cell lines that stably expressed full-length Tat (Tat101) and deletion mutants (Tat86, Tat72, Tat48 and Tat $\Delta$ ). These cell lines were then incubated with SMX-HA and assayed for cell viability and production of reactive oxygen species (ROS). We further used confocal microscopy to assess the intracellular distribution of the Tat proteins and to determine if changes in the expression and/or localization of key cytoskeleton proteins contributed to Tat-mediated apoptosis after SMX-HA treatment.

Results: Deletion of regions of Tat that lead to increased cytoplasmic accumulation significantly contributed to increased cell death in the presence of SMX-HA. The increased cell death did not require induction of ROS. Quantitative analysis also showed that the Tat-expressing cell lines had significantly lower levels of $\beta$-actin and $\alpha$-tubulin present both before and after treatment with SMX-HA. Increased cytoplasmic localization of Tat correlated with greater disturbances in the distribution of actin filaments.

Conclusion: The presence of cytoplasmic Tat in T and epithelial cell lines increases their sensitivity to SMX-HA induced cell death, an effect mediated by the first 48 amino acids of TAT.

Keywords: HIV-1 Tat; Jurkat T cell; Cos 7; Sulphamethoxazole; Sulphamethoxazole-hydroxylamine; Hypersensitivity adverse drug reactions

List of Abbreviations: ADRs: Adverse Drug Reactions; AIDS: Acquired Immuno Deficiency Syndrome; HIV-1: Human Immunodeficiency Virus type 1; LTR: Long Terminal Repeat; NLS: Nuclear Localization Sequence; PCAF: P300/CREB-binding protein Associated Factor; PTD: Protein Transduction Domain; P-TEFb: Positive Transcriptional Elongation Factor b; ROS: Reactive Oxygen Species; SMX: Sulphamethoxazole; SMX-HA: SulphamethoxazoleHydroxylamine; SMX-TMP: Sulphamethoxazole-Trimethoprim; TAR: Tat Activation Region; Tat: Transactivator of transcription

\section{Introduction}

An important consequence of human immunodeficiency virus type 1 (HIV-1) infection is the decline of the individual's immune system, which allows for vulnerability to opportunistic diseases. The fungus Pneumocystis jirovecii takes advantage of this immunodeficiency to elicit Pneumocystis pneumonia, a lung infection that is commonly treated with the antimicrobial sulphamethoxazole-trimethoprim (SMX-TMP), more commonly known as cotrimoxazole. This standard combination of two antimicrobials is also used to treat urinary tract infections in the HIV-1-negative population. The SMX moiety of the drug has been associated with risk of adverse drug reactions (ADRs) at an incidence of 2-5\% [1]. However, the incidence of SMX ADRs increases to $50 \%$ or more in HIV-1 infected individuals as progression to AIDS occurs [1]. ADRs are conventionally defined as a response to a drug that is noxious and unintended, occurring at doses normally used for prophylaxis or treatment [2]. One of the most serious types of ADRs are the hypersensitivity ADRs which usually present as a delayed reaction characterized by the onset of fever and a rash that can often develop into serious skin conditions such as Stevens-Johnson syndrome or toxic epidermal necrolysis, both of which can be fatal [2]. Clinical manifestations of hypersensitivity ADRs are highly diverse and often involve numerous organs such as the liver and kidneys [2]. These symptoms are similar in HIV-1-infected and uninfected patients, however severe reactions such as Stevens-Johnson syndrome or toxic epidermal necrolysis are much more common in HIV-1infected individuals [3]. The risk of an SMX-induced ADR significantly increases as HIV-1 infection progresses to AIDS, specifically when HIV-1 infection is uncontrolled which suggests that virus infection can adversely modify the manner in which host-drug interactions take place.

The hapten hypothesis has been advanced as being key to the pathogenesis of drug hypersensitivity in general and those stimulated

*Corresponding author: Dekaban GA, Scientist, BioTherapeutics Research Laboratory Director, Molecular Medicine, Robarts Research Institute, Professor Department of Microbiology and Immunology, University of Western Ontario, 1151 Richmond Street North London, Ontario, Canada, Tel: + 519-931-5777; E-mail: dekaban@robarts.ca

Received May 25, 2016; Accepted June 13, 2016; Published June 20, 2016

Citation: Adeyanju K, Dekaban GA, Rieder MJ (2016) Cytoplasmic Distribution of HIV-1 Tat Sensitizes Jurkat T cells to Sulphamethoxazole-Hydroxylamine Induced Toxicity. HIV Curr Res 1: 105.

Copyright: (c 2016 Adeyanju K, et al. This is an open-access article distributed under the terms of the Creative Commons Attribution License, which permits unrestricted use, distribution, and reproduction in any medium, provided the original author and source are credited. 
by SMX in particular. This hypothesis postulates that bioactivation and haptenation of the drug to a cellular protein or proteins is critical to the initiation of an immune response. Sulphamethoxazole undergoes bioactivation by the cytochrome P450 enzyme CYP2C9 to its hydroxylamine metabolite that is then auto-oxidized to nitroso-SMX, both of which are known to be toxic to cells in vitro [4,5]. Indeed, this toxicity was the basis for an in vitro model of hypersensitivity ADRs as peripheral blood lymphocytes from patients with a history of hypersensitivity ADRs showed significantly increased toxicity across a concentration range of SMX-HA compared to those from controls and patients with a history of non-hypersensitivity reactions [6]. A similar finding was reported in HIV-1-positive patients where SMX-HA cytotoxicity was greater in patients known to exhibit hypersensitivity ADRs [7] and, as we previously demonstrated, also correlated with HIV-1 infection in established T cell lines and with the expression of recombinant HIV-1 Tat (Transactivator of transcription) protein in $\mathrm{T}$ cell lines $[4,8]$.

Tat is a small, non-structural transcriptional regulator essential for the efficient replication of HIV-1. Tat binds to the TAR (Tat activation region) sequence, a stable RNA hairpin that forms at the end of all nascent viral transcripts, which leads to the recruitment and activation of cellular factors that potentiate RNA polymerase II to synthesize fulllength HIV-1 transcripts [9]. The coding sequences of the Tat gene are located on two exons and the resultant protein has a molecular weight of 14-16 kDa. Tat is made up of 101 amino acids with residues 1-72 encoded by the first exon and residues 73-101 encoded by the second exon. The 101 amino acid form of Tat is what is found predominantly in clinical isolates from all HIV-1 subtypes except subtype D, which has a non-synonymous single nucleotide polymorphism creating a stop codon in the second exon and an 86 amino acid protein [10]. Though a few laboratory strains exist that express an 86 amino acid form of Tat, this version is thought to represent an artificially truncated protein $[11,12]$.

The full-length Tat protein can be divided into six domains: the $\mathrm{N}$-terminal domain (aa 1-21), cysteine-rich domain (aa 22-37), core domain (aa 38-47), basic domain (aa 48-60), glutamine-rich domain (aa 61-72) and the C-terminal domain (aa 73-101) [10,13]. The first three domains (aa 1-48) together contain the minimum activation domain of the protein which mediates its interactions with cellular transcription machinery $[9,14,15]$. The basic domain in conjunction with the glutamine-rich domain confers the Tat activation region (TAR) RNA binding properties to Tat. Therefore the product of the first exon (aa 1-72), representing the activation domains and the TAR-binding region, is all that is required for functional HIV-1 transactivating activity. The basic domain is also known as the protein transduction domain (PTD) and contains a nuclear localization sequence (NLS). The PTD confers on Tat the ability to exit HIV-1 infected cells and enter uninfected bystander cells. This form of Tat is known as extracellular Tat and is able to modulate gene expression of a number of cellular genes in both infected and uninfected cells $[9,16]$. Ultimately, extracellular Tat is thought to facilitate the spread and pathogenesis of HIV-1 by contributing to the apoptosis and eventual depletion of the $\mathrm{CD} 4^{+} \mathrm{T}$ cell subset [17-20].

We have previously demonstrated SMX-HA induced cell death via apoptosis in a cultured T cell line expressing the first exon of the HIV1 Tat protein [21]. Here we determine the mechanism by which SMX -HA enhances Tat's ability to promote apoptosis using the full-length form of Tat. One mechanism by which Tat has been demonstrated to enhance apoptosis is by the production of reactive oxygen species (ROS)
[12], therefore we looked at ROS production in the Tat-expressing cell lines in the absence and presence of SMX-HA. Another pro-apoptotic mechanism utilized by extracellular Tat involves its specific interaction with the $\alpha \beta$-tubulin dimer and polymerized microtubules of the cytoskeleton [22]. This Tat-tubulin interaction is dependent on residues 36-39 which is a four-amino-acid subdomain that overlaps with the core domain [22]. Tat has also been shown to affect the rearrangement of the actin cytoskeleton [23]. In the current study we determined which region of the Tat protein facilitated the cellular toxicity to SMX$\mathrm{HA}$ and if there was any correlation to the expression of cytoskeletal proteins. We also determined if changes in the expression and/or localization of key cytoskeleton proteins enhances apoptosis of Jurkat $\mathrm{T}$ cells expressing intracellular Tat, when the protein is synthesized inside the cell as during an HIV-1 infection. We provide new evidence that in the presence of both HIV-1 Tat and SMX-HA, a T cell is more susceptible to apoptotic cell death and may be the first step in a cascade of events that leads to the increase in SMX-associated ADR in HIV-1 infected persons.

\section{Materials and Methods}

\section{Cell lines}

The human T lymphocyte cell line Jurkat E6.1 (ATCC TIB-152), was obtained from the American Type Culture Collection (ATCC). The cell line was maintained in Complete RPMI 1640 medium (Invitrogen) supplemented with $1 \% \mathrm{~L}$-glutamine, $10 \%$ fetal calf serum and 100 units/ml of penicillin and streptomycin. The Cos-7 cell line (ATCC CRL 1651), a monkey kidney fibroblast-like cell line was maintained in Dulbecco's Modified Eagle's Medium (DMEM) containing 10\% fetal calf serum and 100 units/ml of penicillin and streptomycin.

Construction of plasmids and cell lines: The Tat gene was PCRamplified from the plasmid pSVTat. This plasmid encodes the fulllength Tat gene and was a kind gift from Dr. KT Jeang at the Laboratory of Molecular Microbiology, the Molecular Virology Section, NIAID, NIH. The full-length Tat gene (Tat101), with or without stop codons, and Tat deletion mutants (Tat86, Tat72, Tat48 and Tat $\Delta(49-59)$ ) were cloned into the plasmid pEGFP-N1 (Clontech Inc.), resulting in Tat101, Tat101GFP, Tat86GFP, Tat72GFP, Tat48GFP and Tat $\Delta$ GFP fusion gene, respectively. The fusion genes were then subcloned into pBIG2i as previously described [21]. The results were the following plasmid constructs; pBIG Tat101, pBIG Tat101GFP, pBIG Tat86GFP, pBIG Tat72GFP, pBIG Tat 48 GFP and pBIG Tat $\triangle$ GFP. As a control, the GFP gene from pEGFP-N1 was also cloned into pBIG2i to create pBIG GFP. The pBIG Tat constructs or pBIG GFP were transfected into Jurkat E6.1 T cells by nucleofection (Lonza, Amaxa Nucleofector) according to the manufacturer's instructions and stable cell lines were generated as previously described [21]. Cos-7 cells were also transfected with the pBIG TatGFP constructs for confocal microscopy studies. The expression of the fusion proteins or GFP in either cell type was induced by incubating the transfected cells with doxycycline (Sigma, Canada).

\section{Source of SMX-HA}

SMX-HA was synthesized by Katarina Sapeta in the laboratory of Dr. Michael A. Kerr at the Department of Chemistry, the University of Western Ontario.

Dose response and time course of doxycycline induction: The concentration of doxycycline required to induce expression of the TatGFP fusion proteins was determined in dose-response experiments where cells from the different cell lines were incubated with 0-1000 $\mathrm{ng} / \mathrm{ml}$ of doxycycline for $40 \mathrm{~h}$ and then the cells were analyzed on a 
FACS (fluorescence-activated cell sorting) Calibur instrument (Becton Dickinson). Time course experiments were conducted by incubating cells with $0-1000 \mathrm{ng} / \mathrm{ml}$ of doxycycline for $72 \mathrm{~h}$, with aliquots taken at $12 \mathrm{~h}$ intervals and analyzed by flow cytometry on a FACS Calibur. In both the dose response and time course experiments at least 10,000-gated events were measured for each sample. Flow cytometry data were analyzed and the percentage of GFP+ cells determined using the FlowJo program (Tree Star, Inc.).

\section{Real time PCR analyses of Tat/GAPDH mRNA levels}

To compare the level of Tat mRNA present in the stable cell lines with that in HIV-1-infected cells, cells from each of the stable pBIG TatGFP cell lines were induced by treatment with $0,200,400,600,800$ and $1000 \mathrm{ng} / \mathrm{ml}$ doxycycline for $40 \mathrm{~h}$ and total RNA was extracted using the RNeasy Mini Kit (Qiagen) according to manufacturer's instructions. RNA was also isolated from HIV-1IIIB-infected Jurkat $T$ cells. Total RNA $(10 \mu \mathrm{g})$ was reverse transcribed using the High Capacity cDNA Archive Kit (Applied Biosystems) according to the manufacturer's instructions. Control real time-PCR reactions were performed in the absence of cDNA templates and GAPDH was used as a control housekeeping gene. Real time-PCR analysis was performed using the ABI PRISM 7900HT Sequence Detection System (Applied Biosystems) with TaqMan assays. Relative expression levels were determined by the comparative cycle threshold method [24].

\section{Western blot analysis}

To characterize the expression of the TatGFP fusion proteins in the Jurkat $\mathrm{T}$ cell lines, cells were differentially induced with doxycycline for $40 \mathrm{~h}$, washed twice in PBS then solubilized with RIPA buffer containing $50 \mathrm{mM}$ Tris- $\mathrm{HCl} \mathrm{pH}$ 7.4, $150 \mathrm{mM} \mathrm{NaCl}, 1 \%$ Triton $\mathrm{x}-100,1 \%$ Sodium deoxycholate, $0.1 \%$ SDS, $1 \mathrm{mM}$ EDTA and complete mini protease inhibitor cocktail (Roche). The lysates were sonicated for $2 \times 20 \mathrm{sec}$ then centrifuged at $13,000 \mathrm{rpm}$ for $15 \mathrm{~min}$ at $4^{\circ} \mathrm{C}$. The supernatants were collected and the protein concentrations were determined using the DC Protein Assay (BioRad) and bovine serum albumin (BSA) as standards. The proteins were resolved on a 15\% SDS-PAGE gel, transferred to a PVDF (polyvinylidene difluoride) membrane and probed for Tat (Advanced Biotechnologies Inc.). Bound antibody was detected using goat anti-mouse horseradish peroxidase-conjugated secondary antibody and enhanced chemiluminescence (Amersham). GAPDH (Sigma) was used as a control for protein loading.

Tat-expressing Cos-7 cells were seeded in 6-well plates at a density of $2 \times 10^{5}$ cells/well and induced with 0,200 or $2000 \mathrm{ng} / \mathrm{ml}$ doxycycline for $40 \mathrm{~h}$. The cells were washed with PBS and treated with $0.05 \%$ DMSO (vehicle) or $200 \mu \mathrm{M}$ SMX-HA diluted in HEPES buffer for $2 \mathrm{~h}$ at $37^{\circ} \mathrm{C}$. This was followed by another $2 \mathrm{~h}$ incubation with media at $37^{\circ} \mathrm{C}$ after which the cells were collected and protein extracted as stated above. $1 \mu \mathrm{g}$ of BSA was added to each $20 \mu \mathrm{g}$ sample of protein that was then resolved on $12 \%$ SDS-PAGE. The proteins were transferred onto PVDF membranes and probed with anti- $\alpha$-tubulin (Sigma Aldrich), anti- $\beta$-actin (Sigma Aldrich) or anti-BSA (Life Technologies) antibodies. Densitometric analysis was performed with FlouChem Q (AlphaInnotech) using BSA as a loading control.

\section{MTT cell viability assay}

Drug toxicity was measured using the MTT (3-(4, 5-dimethylthiazol-2-yl)-2, 5-diphenyltetrazolium bromide; SigmaAldrich) cell proliferation assay. Cell proliferation was quantified by colorimetric conversion of MTT [25]. Briefly, Jurkat pBIG TatGFP cells were differentially induced with doxycycline for $40 \mathrm{~h}$, washed twice with PBS then $7.5 \times 10^{4}$ cells/well were seeded in 96-well plates and incubated in HEPES buffer with $200 \mu \mathrm{M}$ SMX (Sigma-Aldrich) or 0-400 $\mu \mathrm{M}$ of SMX-HA for $2 \mathrm{~h}$. After the drug was removed, the cells were resuspended in media and incubated at $37^{\circ} \mathrm{C}$ for $18 \mathrm{~h}$. Next, 1 $\mathrm{mg} / \mathrm{ml} \mathrm{MTT}$ was added to the wells and incubated at $37^{\circ} \mathrm{C}$ for another $4 \mathrm{~h}$. The reaction product that precipitated was solubilized overnight at room temperature by the addition of the stop solution $(50 \% \mathrm{~N}$, $\mathrm{N}$-dimethylformamide/ $20 \%$ SDS) to the wells. The following morning the absorbance in the wells was determined by an ELISA plate reader at $590 \mathrm{~nm}$ and equated to the percentage of viable cells with the help of a standard curve. This assay was performed on three separate occasions for each cell line.

\section{Detection of reactive oxygen species}

Following the $40 \mathrm{~h}$ doxycycline induction, the cells were washed twice in PBS and resuspended in HBSS (Hank's buffered saline solution) at a concentration of $1 \times 10^{6} \mathrm{cells} / \mathrm{ml}$. Cell suspension $(100 \mu \mathrm{l})$ was placed in wells of a 96-well plate, the plate centrifuged at $1500 \mathrm{rpm}$ for $5 \mathrm{~min}$ and the supernatant decanted. To each well $100 \mu$ lof $20 \mu \mathrm{M}$ DCFH-DA (2', 7'-dichlorfluorescein-diacetate, Sigma) in HBSS was added and the plate was incubated at $37^{\circ} \mathrm{C}$ for $1 \mathrm{~h}$ after which the plate was centrifuged at $1500 \mathrm{rpm}$ for $5 \mathrm{~min}$ and the supernatant decanted. The wells were filled with $100 \mu \mathrm{l} \mathrm{HBSS}$ and background fluorescence read at $485 \mathrm{~nm}$ excitation and $527 \mathrm{~nm}$ emission. SMX-HA was added to the wells in quadruplicates and the plate is incubated at $37^{\circ} \mathrm{C}$ with fluorescence readings at $30 \mathrm{~min}$ intervals for $2 \mathrm{~h}$. This assay was performed on three separate occasions for each cell line.

\section{Confocal microscopy}

Mitochondrial imaging - Cos 7 pBIG TatGFP cells were incubated with $500 \mathrm{ng} / \mathrm{ml}$ of doxycycline for $40 \mathrm{~h}$, incubated with $6 \mu \mathrm{M}$ MitoTracker Far Red (Invitrogen) and $10 \mu \mathrm{M}$ Hoechst 33258 (Sigma-Aldrich) for 20 $\min$ at $37^{\circ} \mathrm{C}$.

Cytoskeletal imaging - Cos 7 cells were incubated with $500 \mathrm{ng} /$ $\mathrm{ml}$ of doxycycline for $40 \mathrm{~h}$, treated with $200 \mu \mathrm{M}$ SMX-HA for $2 \mathrm{~h}$ at $37^{\circ} \mathrm{C}$ and then incubated with media only for an additional $2 \mathrm{~h}$, again at $37^{\circ} \mathrm{C}$. The cells were stained with $10 \mu \mathrm{M}$ Hoechst 33258 for $15 \mathrm{~min}$ at $37^{\circ} \mathrm{C}$, then washed with PBS, fixed with $1 \%$ paraformaldehyde (PFA) for $10 \mathrm{~min}$ at room temperature and permeabilized with cold acetone at $-20^{\circ} \mathrm{C}$ for $4 \mathrm{~min}$. The rest of the procedure was carried out at room temperature. Cells were washed thrice with PBS, blocked with $1 \%$ BSA for $30 \mathrm{~min}$ and then incubated with mouse monoclonal anti- $\alpha$-tubulin (Sigma Aldrich) for $30 \mathrm{~min}$. After three more washes with PBS the cells were incubated with Alexa Flour 633 goat anti-mouse IgG (Molecular Probes) for $30 \mathrm{~min}$ and then Alexa Flour 546 phalloidin (Molecular Probes) was added for $20 \mathrm{~min}$.

The images were taken with a Zeiss LSM 510 META confocal microscope and processed using Image-Pro 5.0 (Media Cybernetics) and Adobe Photoshop CS2 (Adobe Systems, Inc.). The actin proteins were pseudocoloured.

\section{Statistics}

MTT cell viability data were analyzed in GraphPad Prism version 5 (GraphPad Software Inc., San Diego, CA). A two-way ANOVA with Bonferonni's post hoc procedure was used to compare mean differences between groups for different concentration levels. The LC50 values were calculated using GraphPad Prism 5, where the X values (concentration of SMX-HA) were log-transformed and the Y values (\% cell viability) were normalized to define $0 \%$ and $100 \%$ as the smallest and highest 
values, respectively. This was followed by sigmoidal dose-response (variable slope) curve-fit. GraphPad Prism (GraphPad Software Inc., San Diego, CA) was also used to calculate mean and standard error for the real time-PCR data as well as the western blot densitometer data.

\section{Results}

\section{TatGFP constructs}

As we have previously established that $\mathrm{T}$ cells undergo apoptosis when expressing HIV-1 Tat and exposed to SMX-HA $(8,21)$, we wanted to understand the mechanism(s) behind the increased sensitivity to SMX-HA including what regions or properties of Tat contributed to this process. We began by constructing and expressing full length Tat and Tat deletion mutants (Figure 1) fused to EGFP as previously described [21]. Briefly, the full-length HIV-1 Tat protein (Tat101) was PCR amplified and subcloned onto the N-terminal end of an EGFP plasmid to create the fusion protein Tat101GFP. Five deletion mutants of the Tat protein were similarly generated to produce the TatEGFP fusion protein constructs Tat48GFP, Tat72GFP, Tat86GFP and Tat $\Delta$ GFP, which expressed the full-length protein without the NLS/ PTD. The fusion constructs were inserted into a doxycycline-inducible vector pBIG2i and subsequently used to establish stably transfected Jurkat E6.1 T and Cos-7 cell lines derived from single cell clones.

\section{Characterization of the TatGFP-expressing cell lines}

Each stably transfected Jurkat $\mathrm{T}$ cell line was characterized by western blotting to determine if the Tat portion of the correct fusion proteins was present. To this end, cells from each of the lines were incubated for $40 \mathrm{~h}$ with $0-1000 \mathrm{ng} / \mathrm{ml}$ Dox then lysed and protein extracted. The use of specific anti-Tat antibodies showed the induction of the TatGFP fusion protein of the correct size in each of the cell lines at different concentrations of doxycycline (Figure 1). An analogous experiment was carried out with stably transfected Cos7 cells that were incubated with $0-2000 \mathrm{ng} / \mathrm{ml}$ Dox before protein extraction. The increasing expression of the TatGFP proteins was observed in these cell lines, similar to that seen in the Jurkat cell lines (data not shown).

Time course experiments were carried out to determine the induction profile of each Tat fusion protein expression at different doxycycline concentrations as well as the point at which the cell lines were maximally induced for the expression of their various TatGFP fusion proteins. The different cell lines were incubated with 0-1000 ng/ $\mathrm{ml}$ of doxycycline and aliquots taken at various time points and analyzed by flow cytometry. The cell lines expressing Tat and its deletion mutants demonstrated very similar kinetics of GFP induction. In all the cell lines, increasing the concentration of doxycycline produced an increase in the percentages of GFP-expressing cells at every time point (Figure 2). The exact percentage of GFP-expressing cells at each concentration of doxycycline tested differed slightly for each of the cell lines. However, the maximal level of induction at $500-1000 \mathrm{ng} / \mathrm{ml}$ doxycycline was able to induce at least $85 \%$ of the cells to express GFP in all tested cell lines. In addition, GFP expression generally began to plateau at the $36 \mathrm{~h}$ time point and was maintained for at least the $72 \mathrm{~h}$ period, the longest time tested in these experiments. In four of the five cell lines (Tat101GFP, Tat72GFP, Tat86GFP and Tat $\Delta$ GFP), there were a negligible percentage of cells exhibiting GFP fluorescence in the absence of doxycycline (0ng/ $\mathrm{ml}$ ). The exception was the Tat48GFP cell line, where at the initial time point approximately $6 \%$ of cells had detectable levels of GFP fluorescence in the absence of doxycycline (0ng/ml) (Figure 2).

In an effort to compare the level of Tat expression in the engineered cell lines to that in chronically HIV-1-infected cells, quantitative real
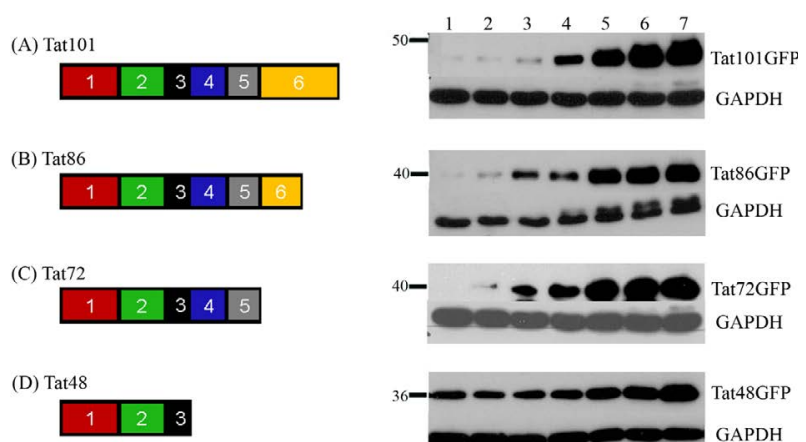

(E) Tat $\Delta$
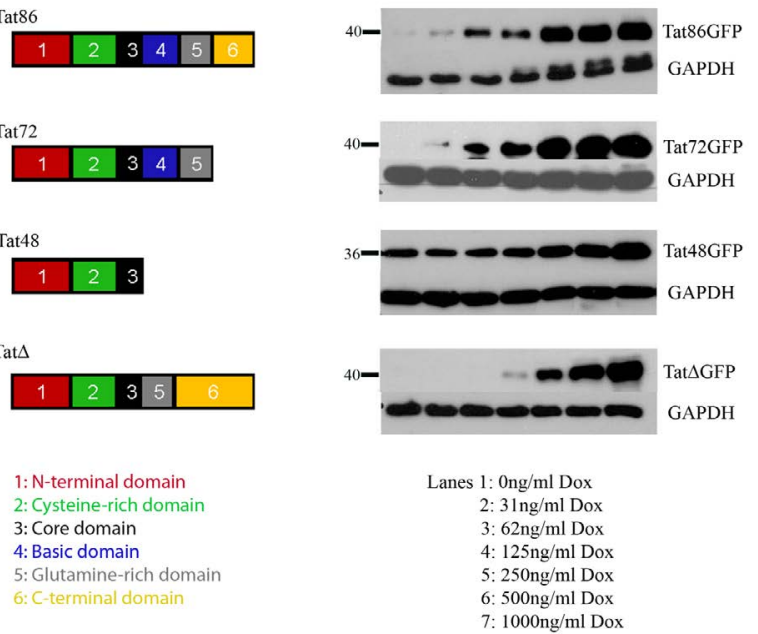

Figure 1: Expression of Tat constructs after differential induction. The left panel shows the functional domains of the various Tat constructs and on the right is the expression of the respective proteins from the constructs after differential induction by doxycycline. Cells from the (A) Tat101GFP, (B) Tat86GFP, (C) Tat72GFP, (D) Tat48GFP and (E) Tat $\Delta$ GFP lines were treated with different concentrations of doxycycline $(0-1000 \mathrm{ng} / \mathrm{ml})$ for $40 \mathrm{~h}$ and then the cells were lysed and protein extracted. The proteins were analyzed on SDS-PAGE and membranes blotted with anti-Tat antibodies. GAPDH was used as a loading control. Data are representative of two independent experiments.
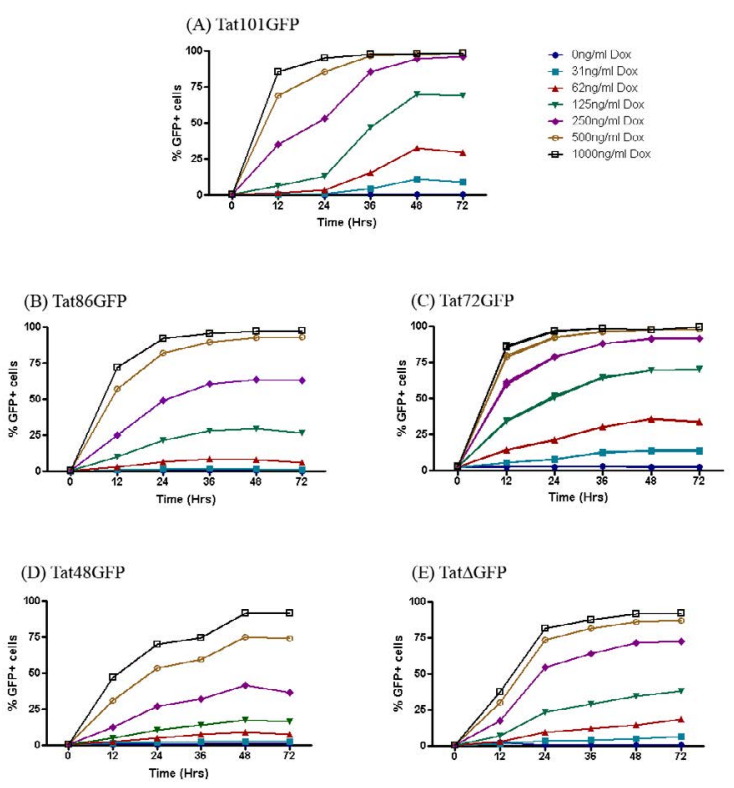

Figure 2: Time course of TatGFP expression following differentia doxycycline induction. Cells from (A) Tat101GFP, (B) Tat86GFP, (C) Tat72GFP, (D) Tat48GFP, and (E) Tat $\triangle$ GFP lines were treated with various concentrations of doxycycline then incubated for $72 \mathrm{~h}$. Aliquots of cells were analyzed by flow cytometry (Calibur) for GFP expression at six different time points. Data are mean of three independent experiments. 
time PCR was performed. This was necessary as the Tat protein in the HIV-1-infected Jurkat T cells (Jurkat-HIV-1) was undetectable via western blots. Using primers specific for spliced Tat mRNA, quantitative PCR detected Tat mRNA in all the cell lines as well as in the Jurkat-HIV-1 cells. The results showed that Tat mRNA expression in the TatGFP cell lines increased as the concentration of doxycycline was increased from $0-1000 \mathrm{ng} / \mathrm{ml}$. Furthermore, the amount of Tat mRNA detected in the Jurkat-HIV-1 cells was comparable to that seen in the TatGFP cell lines though the concentration of doxycycline needed to reach equivalent levels of Tat mRNA differed for each cell line (Figure 3 ). The concentrations of Dox that gave the equivalent concentration of Tat mRNA in HIV-1 infected cells was used in all subsequent experiments unless indicated otherwise in order that the level of Tat was physiologically relevant to that of an HIV-1 infected $\mathrm{T}$ cell.

\section{Intracellular localization of TatGFP constructs}

Studies have previously shown that fusion proteins utilizing the PTD of the Tat protein are transported into the mitochondria from outside the cell [26]. To determine if Tat synthesized in the cell (intracellular Tat) enters the mitochondria, confocal microscopy was used to visualize the intracellular localization of the different TatGFP proteins following transfection of Cos 7 cells. These experiments were carried out in Cos 7 cells as they are more conducive to this type of image analysis than the smaller, round Jurkat $\mathrm{T}$ cells that have minimal cytoplasm. The cells were induced for Tat expression then stained for mitochondria and for nuclear DNA. The confocal images showed that the GFP fluorescence of the Tat101GFP and Tat72GFP proteins are co-localized with the Hoechst stain in the nucleus (Figure 4), while the mitotracker-stained mitochondria were evenly distributed throughout the cytoplasm (Figure 4(A-C)). The same pattern was seen with Tat86GFP (data not shown). In contrast, both the Tat $\triangle$ GFP and Tat48GFP proteins showed GFP fluorescence both in the nucleus and cytoplasm of the cells. This dispersal of GFP fluorescence was also seen in the corresponding Tatexpressing Jurkat $\mathrm{T}$ cell lines (Supplemental Figure 1). The distribution of the mitochondria in the cytoplasm of the Tat48GFP-expressing cell was similar to that of the other TatGFP fusion proteins (Tat101GFP, Tat86GFP and Tat72GFP, Figure 4D) while mitochondrial aggregation was observed around the nucleus in cells expressing Tat $\Delta$ GFP (Figure $4 \mathrm{E})$. The non-punctate/diffuse nature of the GFP fluorescence in the Tat $\triangle$ GFP and Tat48GFP-expressing cells suggests there was no colocalization between GFP and the relatively structured organization of mitochondria in these cells (Figures 4D and E). One method to quantify protein co-localization within subcellular structures relies on their fluorescent intensity line profiles [27]. An examination of the line profiles for the images from the Tat $\Delta$ GFP and Tat48GFP-expressing cells showed there was no observable colocalization of GFP fluorescence with mitotracker-stained mitochondria (Supplemental Figure 2).

\section{Cell Viability of Tat-expressing cell lines after treatment with SMX-HA}

Earlier studies have consistently demonstrated concentrationdependent toxicity when SMX-HA is incubated with cells from patients with a history of hypersensitivity ADRs to SMX compared to the cells of controls [6]. Our studies have also shown that this effect on viability is amplified in the presence of the Tat protein and is also influenced by the amount of Tat protein in the cell [8]. The Tat-expressing cell lines were used to determine the region or domain of the protein that is involved in enhancing toxicity. These cell lines were evaluated using the MTT cell viability assay and were carried out using un-induced cells (controls) and cells exposed to different concentrations of doxycycline
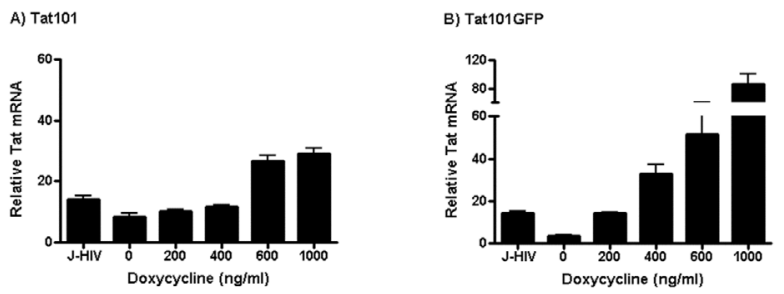

C)

\begin{tabular}{|c|c|c|c|c|c|}
\hline \multirow{2}{*}{$\begin{array}{c}\text { Doxycycline } \\
(\mathbf{n g} / \mathbf{m l})\end{array}$} & \multicolumn{5}{|c|}{ Cell Lines } \\
\cline { 2 - 6 } & Jurkat HIV & Tat86GFP & Tat72GFP & Tat48GFP & Tat $\Delta$ GFP \\
\hline 0 & 14.3 & 1.49 & 1.25 & 1.47 & 0.222 \\
\hline 200 & $\mathrm{n} / \mathrm{a}$ & 14.8 & 1.78 & 2.17 & 11.3 \\
\hline 400 & $\mathrm{n} / \mathrm{a}$ & 26.1 & 5.17 & 3.91 & 33.7 \\
\hline 600 & $\mathrm{n} / \mathrm{a}$ & 26.9 & 18.6 & 6.92 & 38.9 \\
\hline 800 & $\mathrm{n} / \mathrm{a}$ & 38.6 & 53.7 & 8.25 & 44.1 \\
\hline 1000 & $\mathrm{n} / \mathrm{a}$ & 21 & 83.8 & 12.4 & 50.1 \\
\hline
\end{tabular}

Figure 3: Quantification of Tat mRNA in the cell lines (A) Tat101, (B) Tat101GFP and (C) data from the other cell lines. Cells were treated with doxycycline for $40 \mathrm{~h}$ then RNA was extracted. Total RNA $(10 \mu \mathrm{g})$ was reverse transcribed and used to generate a standard curve with GAPDH serving as the housekeeping gene. Tat mRNA was detected using a Tatspecific primer. Data are mean of three independent experiments.

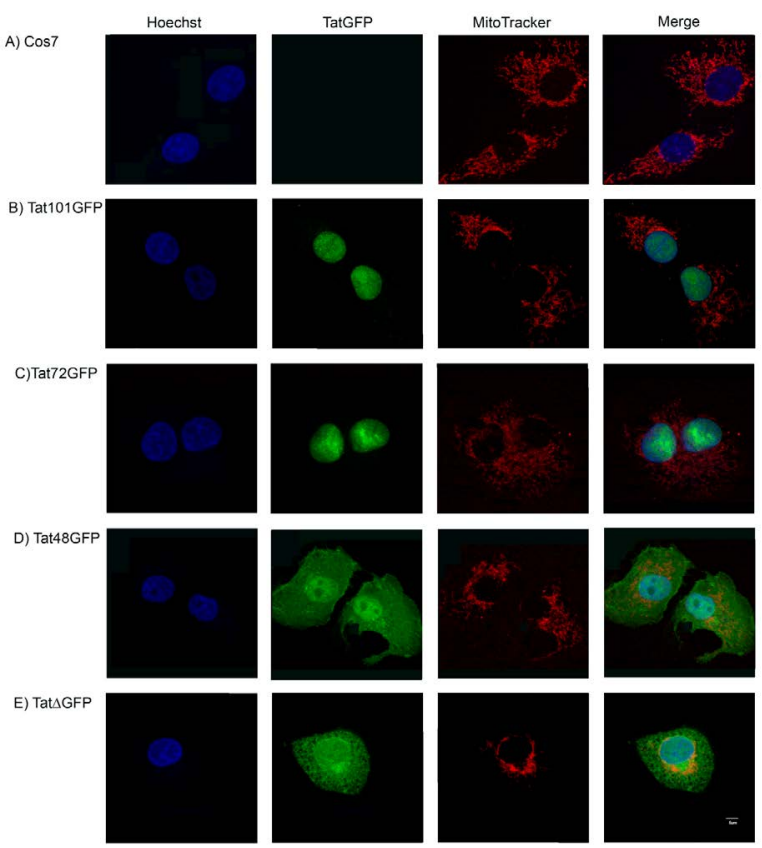

Figure 4: Confocal images showing localization of the Tat constructs and mitochondrial distribution. Cells from (A) Cos, (B) Tat101GFP, (C) Tat72GFP, (D) Tat48GFP, and (E) Tat $\triangle$ GFP lines were treated with doxycycline for $40 \mathrm{~h}$, stained with Mitotracker Red and Hoechst 33258 stain, and then analyzed under a Zeiss LSM 510 META confocal microscope. The scale bar represents $5 \mu \mathrm{m}$.

to induce different amounts of Tat, including that needed to reach the Tat levels of HIV-1 infected Jurkat cells.

As previously demonstrated, neither the pro-drug SMX nor the vehicle DMS0 (0 $\mu$ M SMX-HA) had any significant effect on the cellular viability of Jurkat $\mathrm{T}$ cells as the viability of each of the different cell lines remained above 95\% for the duration of the MTT assay (data 
(A) Tat101

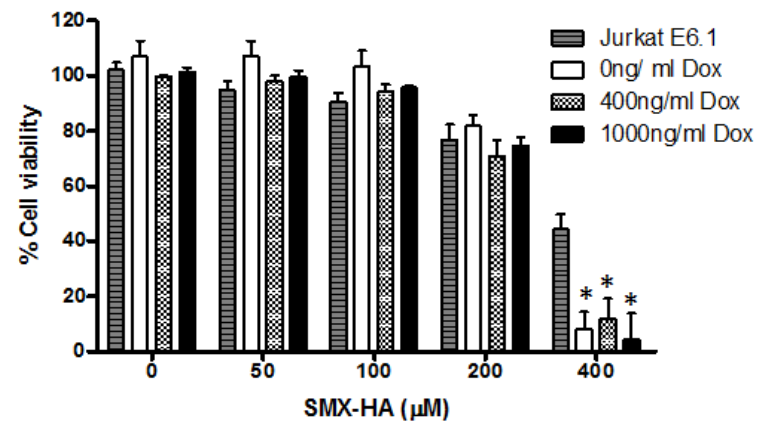

(C) Tat86GFP

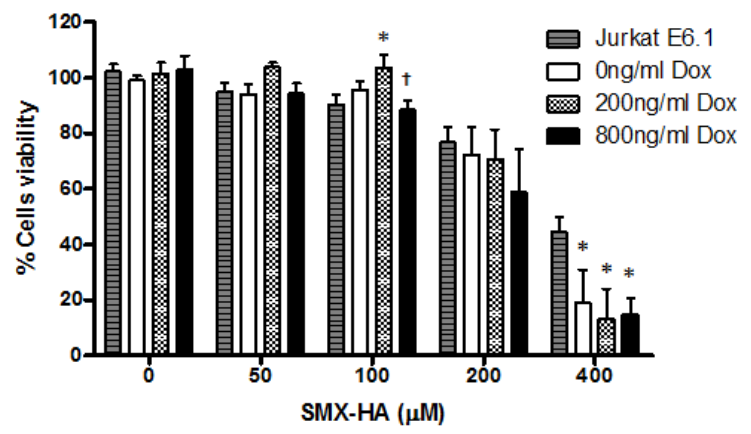

(E) Tat48GFP

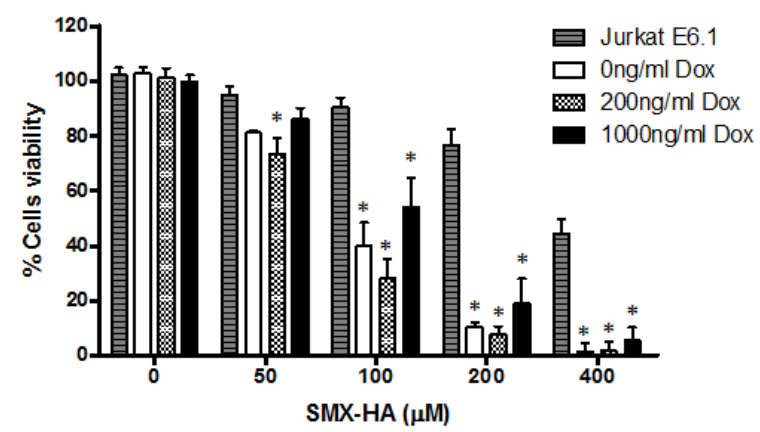

(B) Tat101GFP

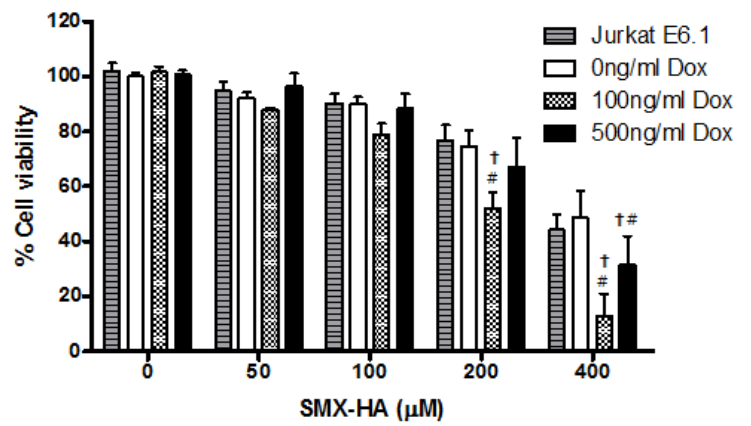

(D) Tat72GFP

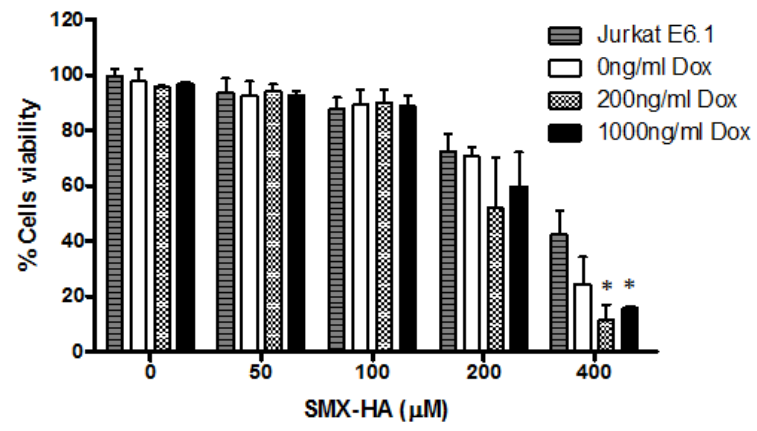

(F) Tat $\triangle$ GFP

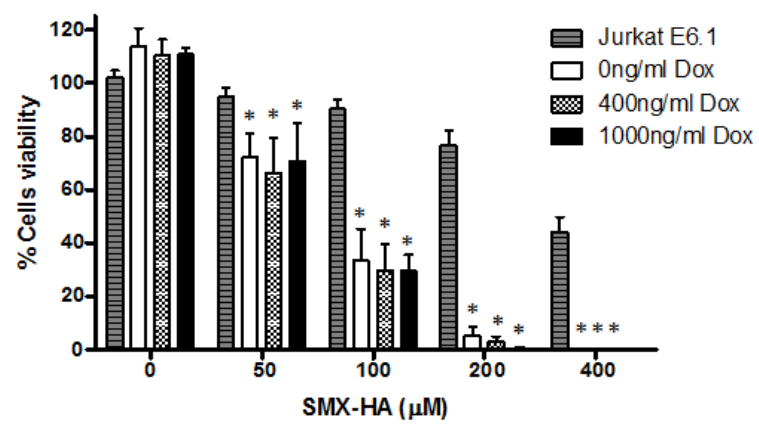

Figure 5: The effect of Tat constructs on cell toxicity in the presence of SMX-HA. Tat expression was induced for $40 \mathrm{~h}$ from (A) Tat101, (B) Tat101GFP, (C) Tat86GFP, (D) Tat72GFP, (E) Tat48GFP or (F) Tat $\Delta$ GFP lines by treatment with various concentrations of doxycycline (0-1000ng/ml) then incubated with $0-400 \mu \mathrm{M}$ SMX-HA for $2 \mathrm{~h}$ after which the drug was replaced with media and the cells incubated at $37^{\circ} \mathrm{C}$. The next day the cells were incubated with $5 \mathrm{mg} / \mathrm{ml}$ of MTT again at $37^{\circ} \mathrm{C}$ for a period of $4 \mathrm{~h}$. The percent cell viability was then determined the following day via a plate reader at $590 \mathrm{~nm}$. Data from each cell line are mean of three independent experiments, with the exception of Jurkat E6.1. The results from the Jurkat E6.1 cells in each panel are the average of 25 different MTT experiments carried out in conjunction with different Tat-expressing cell lines over a course of several months. ${ }^{*} \mathrm{P}<0.001$ vs. Jurkat E6.1.

not shown). While the difference in cell viability between the Tat101expressing and Jurkat E6.1 cells was significant at $400 \mu \mathrm{M}$ SMX-HA, there was no significant difference between the differentially induced Tat 101 cells at this concentration (Figure 5A). Cell toxicity of the Jurkat E6.1 parental cells was significantly different from Tat101GFP cells induced with $100 \mathrm{ng} / \mathrm{ml}$ Dox at $200 \mu \mathrm{M}$ and $400 \mu \mathrm{M}$ SMX-HA (Figure $5 \mathrm{~B})$. While cells induced with $500 \mathrm{ng} / \mathrm{ml}$ doxycycline followed the general trend of decreased cell viability with increasing concentrations of SMX-HA, these cells did not demonstrate changes in viability that were significantly different from doxycycline untreated cells (Figure 5B, $0 \mathrm{ng} / \mathrm{ml}$ Dox).

The Tat86GFP cell line showed a slight increase in the proliferation of cells induced with $200 \mathrm{ng} / \mathrm{ml}$ Dox and treated with 50-100 $\mu \mathrm{M}$ SMX$\mathrm{HA}$ in comparison to the other cell populations (Figure 5C) with a significant increase in cell proliferation compared to Jurkat E6.1 cells at $100 \mu \mathrm{M}$ SMX-HA. As well, there was a significant decrease between the $200 \mathrm{ng} / \mathrm{ml}$ Dox and the $800 \mathrm{ng} / \mathrm{ml}$ Dox cell populations at $100 \mu \mathrm{M}$ SMX-HA (Figure 5C). There was also a significant decrease in viability of the Tat86GFP cells compared to Jurkat E6.1 cells at $400 \mu \mathrm{M}$ SMXHA. The Tat72GFP cell line did not show a significant decrease in cell viability until $400 \mu \mathrm{M}$ SMX-HA (Figure 5D). However, the differential induction of Tat72GFP had no significant effect on cell viability at any concentration of SMX-HA.

In contrast, the Tat $48 \mathrm{GFP}$ and Tat $\Delta \mathrm{GFP}$-expressing cell lines 
demonstrated significant decreases in viability compared to Jurkat E6.1 cells at $50 \mu \mathrm{M}$ SMX-HA, a lower treatment dose than seen with any of the cell lines described above (Fig 5E and 5F). At $100 \mu \mathrm{M}$ SMX-HA, the viability of the $0 \mathrm{ng} / \mathrm{ml}$ population had dropped to approximately $40 \%$, significantly lower than cell viabilities of $90 \%$ and above of the cell lines expressing Tat101, Tat101GFP, Tat86GF or Tat72GFP. Cell viability continued to decrease at the higher concentration of SMX-HA, but there was no significant difference in the differentially induced cells.

Comparing the LC50 (lethal concentration, 50\%) of each of the cell lines demonstrated that both the Tat48GFP and Tat $\Delta$ GFP cell lines were particularly sensitive to SMX-HA. As shown in Table 1, the LC50 values for the Jurkat E6.1, Tat101, Tat101GFP, Tat86GFP and Tat72GFP cell lines were in the concentration range of 200-300 $\mu \mathrm{M}$ SMX-HA while that of Tat 48 GFP and Tat $\triangle$ GFP was 2 -fold to six-fold lower at 67-106 $\mu \mathrm{M}$ and 52-59 $\mu \mathrm{M}$ SMX-HA respectively. In an effort to determine if this phenomenon was clone-specific, the pBIG Tat48GFP and pBIG Tat $\triangle$ GFP DNA was used to transfect Jurkat E6.1 cells and the pool of stably selected transfectants rather than single cell clones was used in the MTT assay. The result was an LC50 of 137-160 $\mu \mathrm{M}$ and $138-149 \mu \mathrm{M}$ respectively. While in both cases these LC50 values were higher than the LC50 found in the assay using specific clones, they were still significantly lower than the other cell lines, indicating that the Tat48GFP and Tat $\Delta$ GFP cell lines were more sensitive to SMX-HAinduced toxicity.

\section{Generation of ROS by Tat-expressing cell lines}

HIV-1 Tat has been reported to induce the formation of reactive oxygen species (ROS) that leads to apoptosis in T cells [12]. To determine if ROS contributed to cell death observed in the MTT assays, the pro-oxidant effects of the Tat protein and its deletion mutants were evaluated. Cells from the various cell lines were induced with doxycycline and then incubated in the presence of SMX or SMX-HA and DCFH, a cell permeable dye whose oxidized form fluoresces in the presence of ROS. Incubation with SMX generated ROS in negligible amounts similar to the fluorescence seen when the cells were incubated with the vehicle DMSO. Significant production of ROS was only evident upon the addition of SMX-HA to each of the cell lines (Figure 6) resulting in a 3 - and 8 -fold increase in ROS produced. In the Tat 101 and Tat101GFP-expressing cell lines, a general trend was observed whereby increases in the doxycycline concentration lead to small, but significant increases in ROS production (Figures 6A and 6B). However, the doxycycline-induced expression of Tat86GFP (Figure 6C), Tat72GFP (Figure 6D), Tat48GFP (Figure 6E) and Tat $\triangle$ GFP (Figure 6F) did not significantly increase ROS production. In contrast, there was a marked difference in the amount of ROS generated by the Tat101, Tat101GFP and Tat86GFP cell lines compared to the other cell lines. Indeed the other cell lines produced far less ROS ( 40-50\% less) in the presence of SMX-HA, indicating that the pro-oxidant effect of Tat depends on the presence of its C-terminal domain. Additionally, this property of Tat seemed to only be effective when the protein was localized to the nucleus, as the ROS generated by the Tat $\Delta$ GFP-expressing cell line in the presence of SMX-HA did not reach the magnitude observed in the Tat101GFP cell line.

\section{Expression and intracellular distribution of actin and tubulin}

The discrepancy between the Tat-expressing cell lines with significant levels of cell death after SMX-HA treatment (Figures 5E and 5F; Tat48GFP and Tat $\triangle$ GFP) and those that produced considerable amounts of ROS in the presence of SMX-HA (Fig 6A and 6B; Tat101 and Tat101GFP) suggested that oxidative stress was not the primary mode of cell death. Therefore, we investigated other mechanisms of Tat-induced cell death. Several studies have illustrated the ability of extracellular Tat to affect the cytoskeleton, mainly by altering cytoskeletal dynamics. Extracellular Tat can cause actin cytoskeletal rearrangements and, at high concentrations, cytoskeletal disassembly and collapse [23-28]. Extracellular HIV-1 Tat has also been shown to bind tubulin, enhance microtubule polymerization and induce apoptosis by causing the formation of abnormally stable microtubules $[22,29,30]$. The contribution of intracellular Tat to changes in the expression and function of cytoskeletal proteins remains undocumented. To determine if this is occurring in the context of SMX-HA treatment, we first induced TatGFP expression with a low (200 ng/ml Dox) and a high (2000 ng/ $\mathrm{ml}$ Dox) concentration of doxycycline in Cos 7 cells stably-expressing the different deletion mutants of Tat. We then looked at changes in the expression of the cytoskeletal proteins $\beta$-actin and $\alpha$-tubulin before and after treatment with SMX-HA. Quantitative analysis showed that the cell line expressing Tat101GFP had significantly lower levels of $\beta$-actin and $\alpha$-tubulin both before and after treatment with SMXHA, suggesting the full-length Tat protein was able to down-regulate these proteins. The expression levels of $\beta$-actin and $\alpha$-tubulin in cells expressing Tat $\Delta$ GFP, Tat48GFP, and Tat72GFP followed in ascending order (Figure 7).

Confocal imaging of untransfected and Tat-expressing Cos 7 cells was also carried out to visualize the intracellular distribution of actin and tubulin proteins after SMX-HA treatment (Figure 8). Of the stablyexpressing TatGFP cell lines examined, those expressing Tat101GFP and Tat72GFP were able to broadly retain the organization of their actin filaments which formed straight lines that traversed the cell. Cells expressing Tat48GFP exhibited the most stress after SMX-HA treatment with the cells generally exhibiting a complete disorganization of the actin filaments that pooled at different parts of the cell, leading to cells with a shrunken appearance. There were no straight lines of actin filaments in the Tat $\Delta \mathrm{GFP}$-expressing cells, but neither was there the aggregation of actin as seen in cells expressing Tat48GFP. Consistent with Tat stabilizing tubulin filaments, the intracellular distribution of $\alpha$-Tubulin was not affected as filaments were seen throughout the cytoplasm of all cells. The images also did not show any discernable interaction between the TatGFP proteins and a-tubulin. These observations were true not only for the nuclear-localized Tat101GFP and Tat72GFP proteins, but also the Tat 48 GFP and Tat $\Delta$ GFP proteins both of which exhibit a significant cytoplasmic distribution. Though there was an increased distribution of $\beta$-actin around the edges of the TatGFP-expressing Jurkat $T$ cells, there was no discernable pattern or structure to the distribution of either $\beta$-actin or $\alpha$-Tubulin within the cells, perhaps due to the limited area of the cytoplasm (Supplemental Figure 3).

\section{Discussion}

Adverse drug reactions occur at a higher frequency in HIV-1positive patients than in the general population [1]. These reactions occur in a number of therapeutic classes, including antiretroviral drugs and the antibiotics used to prevent or treat opportunistic infections. One of the most common drugs responsible for adverse effects in HIV1 -infected individuals is the antimicrobial agent SMX. ADRs to SMX in patients undergoing antiretroviral therapy arise increasingly as HIV-1 infection progresses to AIDS suggesting that HIV-1 is a key contributing factor. Previously, our research has shown that the HIV-1 Tat protein is such a factor as Tat expression correlates with increased sensitivity to SMX-HA, the reactive metabolite of SMX $[8,21]$. In this study we sought to determine the region of the Tat protein mediating this effect. 
Citation: Adeyanju K, Dekaban GA, Rieder MJ (2016) Cytoplasmic Distribution of HIV-1 Tat Sensitizes Jurkat T cells to SulphamethoxazoleHydroxylamine Induced Toxicity. HIV Curr Res 1: 105.

Page 8 of 12

\begin{tabular}{|c|c|c|c|}
\hline Cell Line & Ong/ml Dox & 400ng/ml Dox & $1000 \mathrm{ng} / \mathrm{ml}$ Dox \\
\hline Jurkat E6.1 & 300 & $\mathrm{n} / \mathrm{a}$ & $\mathrm{n} / \mathrm{a}$ \\
\hline Tat101 & 264 & 250 & 243 \\
\hline Tat101GFP & 302 & 156 & 265 \\
\hline Tat86GFP & 328 & 310 & 280 \\
\hline Tat72GFP & 262 & 197 & 228 \\
\hline Tat48GFP & 77 & 67 & 106 \\
\hline Tat $\Delta$ GFP & 59 & 52 & 57 \\
\hline Pooled Tat48GFP & 161 & 162 & 137 \\
\hline Pooled Tat $\Delta$ GFP & 149 & 146 & 138 \\
\hline
\end{tabular}

Table 1: $\mathrm{LC}_{50}$ values of the various Jurkat T cell lines. All the cells used in the experiments were from clone-specific, stably-transfected cell lines with the exception of the two cell lines given the 'pooled' moniker. These pooled cell lines were generated by hygromycin B selection post transfection to create a cell line of multiple clones. LC50 values were calculated using GraphPad Prism v. 5 as described in the methods.
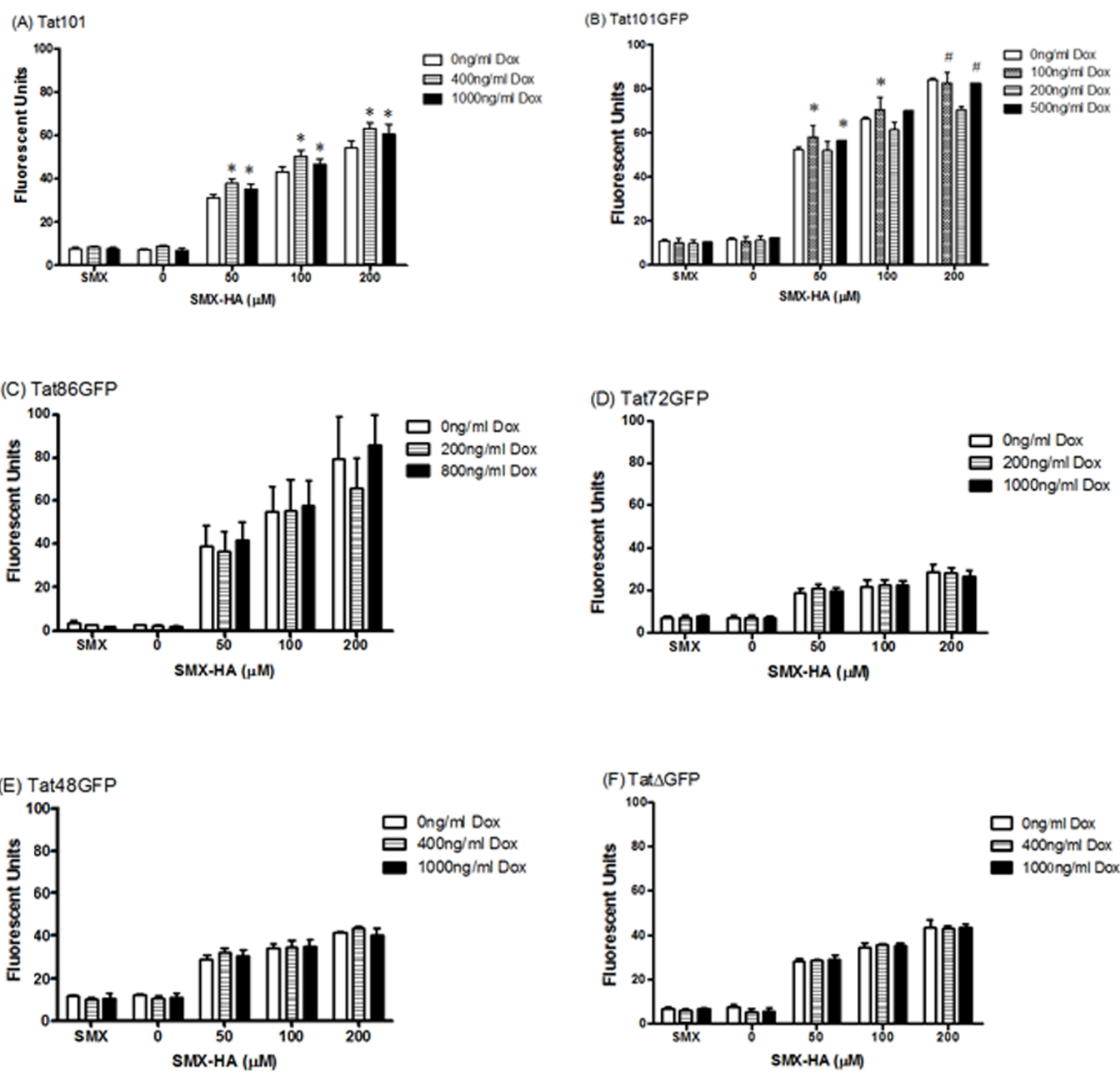

Figure 6: Reactive oxygen species generated in the presence of SMX-HA and the various Tat constructs. After induction with doxycycline, cells from the (A) Tat101, (B) Tat101GFP, (C) Tat86GFP, (D) Tat72GFP, (E) Tat48GFP or (F) Tat $\triangle$ GFP lines were seeded at a concentration of $1 \times 10^{6}$ cells/ml and incubated with $10 \mu \mathrm{M} \mathrm{DCFH}$ at $37^{\circ} \mathrm{C}$ for $1 \mathrm{~h}$. There followed an incubation with different concentrations of SMX-HA for $2 \mathrm{~h}$ at which point the fluorescence was determined via a plate reader. ${ }^{*} \mathrm{P}<0.001 \mathrm{vs}$. Ong/ml Dox (control cells), \#P<0.05 vs. 200ng/ml Dox. Data are mean of three independent experiments. 
Citation: Adeyanju K, Dekaban GA, Rieder MJ (2016) Cytoplasmic Distribution of HIV-1 Tat Sensitizes Jurkat T cells to SulphamethoxazoleHydroxylamine Induced Toxicity. HIV Curr Res 1: 105.

(A)

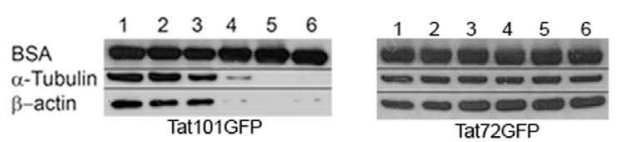

(B)
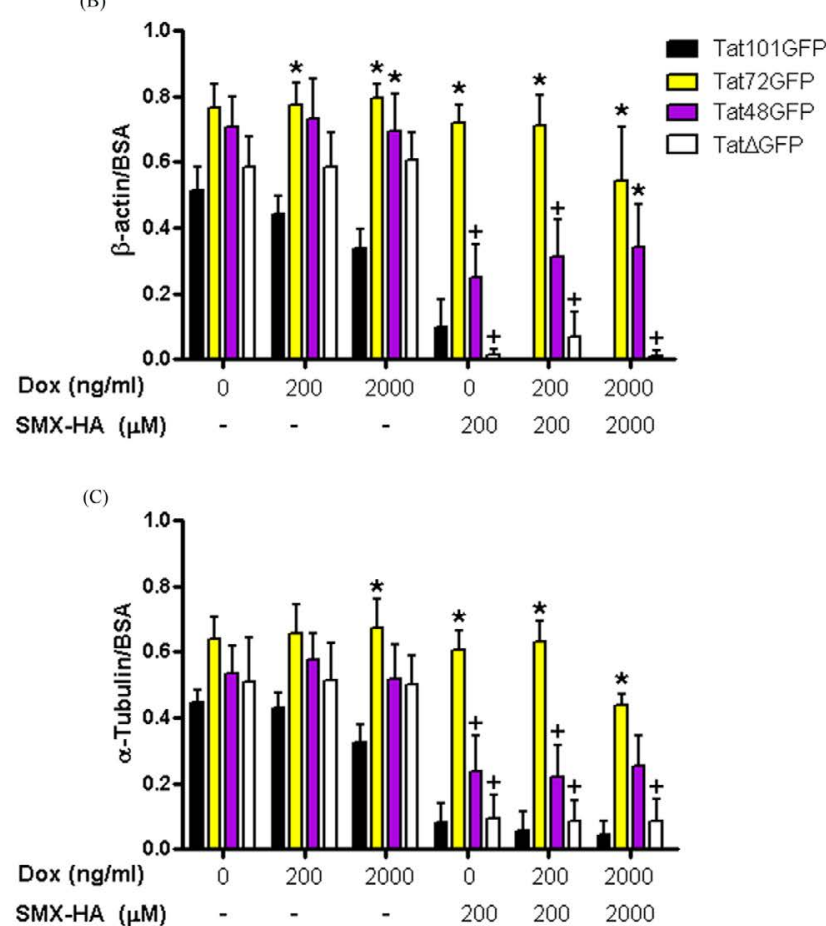

Figure 7: Expression of $\alpha$-tubulin and $\beta$-actin in Tat-expressing cells. (A) Representative western blots showing protein expression from Cos Tat101GFP and Tat72GFP cells. Densitometric analysis of $\beta$-actin (B) and $\alpha$-tubulin (C) expression. The Cos 7 cells were induced with doxycycline for $40 \mathrm{~h}$ and then treated with DMSO or $200 \mu \mathrm{M} \mathrm{SMX-HA}$ for $2 \mathrm{hr}$ at $37^{\circ} \mathrm{C}$ followed by another $2 \mathrm{hr}$ incubation with media at $37^{\circ} \mathrm{C}$. Protein was extracted, analyzed on SDS-PAGE and immunoblotted with anti- $\alpha$-tubulin, anti- $\beta$-actin or anti-BSA antibodies. Exogenous BSA was used as a loading control. Data shows average of fou independent experiments. Lanes 1, 2 and 3 show protein expression from cells induced with $0 \mathrm{ng} / \mathrm{ml}, 200 \mathrm{ng} / \mathrm{ml}$ and $2000 \mathrm{ng} / \mathrm{ml}$ Dox respectively. Lanes 4,5 and 6 show protein expression from cells induced with $0 \mathrm{ng} / \mathrm{ml}, 200 \mathrm{ng} / \mathrm{ml}$ and $2000 \mathrm{ng} / \mathrm{ml}$ Dox respectively, then treated with $200 \mu \mathrm{M}$ SMX-HA. ${ }^{*} \mathrm{P}<0.05$ vs. Tat101GFP, ${ }^{+} p<0.05$ vs. Tat72GFP.

We also wanted to determine whether the presence of intracellular Tat affected tubulin or actin expression levels and adversely affected their normal intracellular organization that can result in increased cell death. To this end, we engineered deletion mutants of Tat fused to GFP and then established stably transfected Jurkat $\mathrm{T}$ and Cos7 cell lines.

Initial experiments were conducted to determine the cellular distribution of the full-length fusion protein as well as the deletion mutants in Cos 7 and Jurkat T cells. As expected, the full-length Tat protein, Tat101GFP, and deletion mutants Tat86GFP and Tat72GFP localized to the nucleus due to the presence of the previously identified nuclear localization sequence/protein transduction domain (NLS/ PTD) $[31,32]$. In contrast, the Tat $48 \mathrm{GFP}$ and Tat $\Delta$ GFP fusion proteins were distributed throughout the cell due to the deletion of the NLS/ PTD, which mediates nucleo-cytoplasmic shuttling of Tat. The detection of GFP fluorescence in the nucleus of the Tat $\Delta$ GFP and Tat 48 GFP cells can be attributed to the association of the Tat proteins

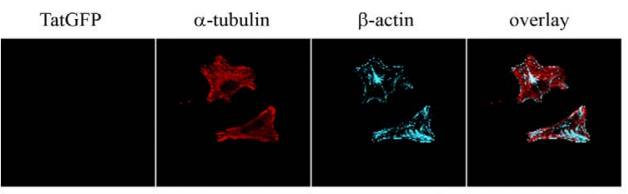

(B) Tat101GFP

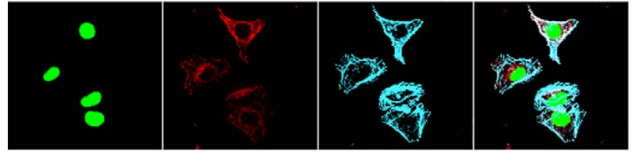

(C) Tat72GFP

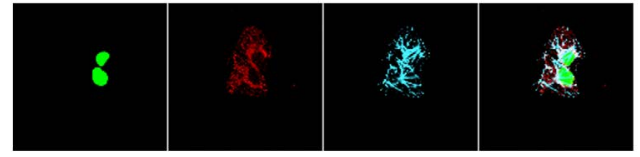

(D) Tat48GFP

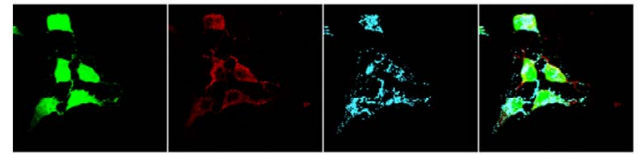

(E) Tat $\Delta$ GFP

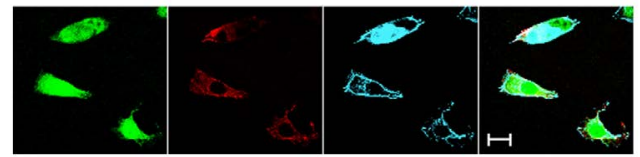

Figure 8: Confocal images showing proteins of the cytoskeleton after treatment with SMX-HA. Cells from (A) Cos 7, (B) Tat101GFP, (C) Tat72GFP, (D) Tat48GFP, and (E) Tat $\triangle$ GFP-expressing lines were treated with doxycycline for $40 \mathrm{~h}$, treated with $200 \mu \mathrm{M} \mathrm{SMX-HA}$ for $2 \mathrm{~h}$ at $37^{\circ} \mathrm{C}$ then incubated in media for another $2 \mathrm{~h}$. The cells were stained with Hoechst 33258 and then fixed with $1 \%$ PFA. $\alpha$-tubulin and $\beta$-actin were visualized by immunofluorescence staining under a Zeiss LSM 510 META confocal microscope. The scale bar represents $20 \mu \mathrm{m}$.

with members of its transcriptional complex such as P-TEFb and PCAF (p300/CREB-binding protein Associated Factor) as the key domains for such interactions are located within the first 48 amino acids of the $\mathrm{N}$-terminus [9,33-35]. The mitochondrial aggregation seen in Tat $\Delta$ GFP-expressing cells may be an indication of an early step towards apoptosis. Studies have shown that mitochondrial dynamics have a significant role in regulating apoptosis. In particular, Haga et al. [36] showed quantitatively via laser scanning cytometry that mitochondrial aggregation precedes cytochrome $\mathrm{c}$ release during apoptosis and that cytochrome $\mathrm{c}$ release is dependent on mitochondrial aggregation. We have previously shown that TatGFP expression increases cytochrome $\mathrm{c}$ release into the cytosol of Jurkat pBIG TatGFP cells upon treatment with SMX-HA [21]. This suggests that Tat $\Delta$ GFP expression, in particular, primes the cell towards apoptosis more effectively than forms of Tat largely restricted to the nucleus, a finding that is consistent with the results of the cell viability assays.

The MTT cell viability assays previously demonstrated a significant increase in cell toxicity in the presence of increasing concentrations of SMX-HA [21]. The differential expression of Tat also had a cooperative effect on SMX-HA-mediated toxicity, significantly decreasing cell viability further as the expression of the TatGFP protein was increased [8]. The failure of Tat72GFP expression in this paper to potentiate SMX-HA-mediated cell death is in contrast to previously published data $[8,21]$. This may be due to the fact that the sequence of the 72 amino acid Tat protein used in the aforementioned publications (TatGFP) differs by eleven amino acids from the Tat protein used in the current study (Tat72GFP). While both Tat variants may have the same inherent transactivating properties it is possible that the amino 
acid differences in the Tat protein used previously impart a greater ability to mediate $\mathrm{T}$ cell apoptosis. Peloponese et al. have proposed that differences in Tat sequence may affect its ability to transactivate the HIV-1 LTR [37]. A similar study carried out by de Mareuil et al. [29] showed that Tat variants from patients categorized as rapid progressors were significantly more potent in tubulin polymerization and apoptosis induction in $\mathrm{T}$ cells [29]. Further experiments are needed to more clearly define the importance of Tat amino acid sequence variation on cell viability and whether different Tat sequence variants confer a greater susceptibility to the development of adverse drug reactions.

The cell death seen via the MTT assays in cells expressing the fulllength Tat proteins (Tat101 and Tat101GFP) may be the result of the generation of excess ROS, consistent with a pro-oxidant role for Tat [12,38-40]. Experiments designed to directly compare the impact of Tat101GFP to Tat101 on cell death, as assessed by the MTT assays, demonstrated that the two constructs were not significantly different from one another (data not shown). However, none of the deletion mutants had the same effect allowing us to conclude that the full-length Tat protein is required for the induction of increased ROS in Jurkat cells. Though previous reports have shown that Tat deletion mutants (Tat72 or Tat86) can induce or augment ROS production in cultured cells, this was observed only with the addition of the recombinant extracellular Tat protein to the cultures [12,38-40]. Despite its ability to induce oxidative stress, expression of the full-length Tat proteins did not cause a significant amount of cell death, even after treatment with SMX-HA. Indeed the cell lines with lowest cell viability in response to SMX-HA treatment (Tat48GFP and Tat $\Delta$ GFP) did not produce significant amounts of ROS. This suggests that ROS and cell death are largely unrelated in this context.

To determine if cell death was due to the effect of Tat expression on cytoskeletal proteins, we carried out western blot analysis, which showed Tat101GFP was able to significantly down-regulate the expression of cytoskeletal proteins $\beta$-actin and $\alpha$-tubulin both before and after SMX-HA treatment. This is in agreement with literature showing the ability of Tat to down-regulate proteins including those located within the cytoplasm [41,42]. The preferential localisation of Tat101GFP to the nucleus and its ability to down-regulate the expression of $\beta$-actin and $\alpha$-tubulin has the effect of reducing the possibility of interaction between the cytoskeletal proteins and Tat101GFP. This in turn ensured that apoptosis was not triggered in these cells as shown in the MTT viability assays. The differences seen between the Tat101GFP- and Tat72GFP-expressing cells in the expression of $\beta$-actin and $\alpha$-tubulin further suggests that the $\mathrm{C}$-terminal domain of Tat is necessary for its role in the down-regulation of these proteins.

One possible explanation for the differences in the behaviour of Tat protein synthesized internally (intracellular Tat) versus Tat protein that enters the cell from the milieu (extracellular Tat) is that intracellular Tat localizes predominantly to the nucleus where it carries out its transactivating activities, while extracellular Tat appears to remain largely in the cytoplasm after being endocytosed where it can enhance the stability of polymerized microtubules and subsequently induce apoptosis $[22,30]$. The ability of extracellular Tat to interact with tubulin in the cytoplasm of the cell requires the collective integrity of amino acids 36-39 as mutation of these four residues to alanine was shown to inhibit this interaction [22,29]. Our Tat48GFP and Tat $\Delta$ GFP deletion mutants retain amino acids 36-39 and also exhibit the greatest reductions in cell viability. Due to the loss of the NLS/ PTD sequence the cytoplasmic concentration of these Tat48GFP and Tat $\Delta$ GFP mutants rose, as they were no longer able to exit the cell across the plasma membrane. Hence, the levels of these Tat mutants in the cytoplasm would be sufficient to bind to tubulin and promote the stabilization of polymerized microtubules in a manner similar to that seen with extracellular Tat. This in turn leads to a lower threshold for apoptosis and higher sensitivity to SMX-HA toxicity. Furthermore, the divergent roles of intra- and extracellular Tat illustrates one of the ways HIV-1 maintains survival of HIV-1-infected cells while causing increased apoptosis of predominantly uninfected bystander cells. Taken together these results also re-enforces the importance of Tat nuclear sequestration, not only in promoting the transcription of the HIV1 provirus, but also in preventing premature cell death before HIV-1 replication and progeny virus production can be completed.

The effect of cytoplasmic or extracellular Tat on microtubule dynamics and the mitochondrial aggregation that was seen in the Tat $\Delta$ GFP-expressing cells might also be related. Studies have found a protein named C19ORF5C to be a dual function microtubule- and mitochondria-associated protein that mediates mitotic cell death [43]. C19ORF5C is also recruited to chemically-stabilized microtubules and accumulates on mitochondria, eventually inducing distinct perinuclear aggregation of the mitochondria and resulting in cell death $[44,45]$. The ability of extracellular Tat to bind tubulin and stabilize microtubule polymerization leading to apoptosis has been well established $[22,29,30]$. Whether or not Tat-stabilized microtubules also recruit C19ORF5C or a similar dual function microtubule- and mitochondria-associated protein to induce mitochondrial aggregation, and subsequently apoptosis, requires further investigation.

\section{Conclusion}

In the general population ADRs are responsible for 3\% of all hospital admissions and occur in $10-20 \%$ of hospital inpatients [46]. Additionally, up to $80 \%$ of HIV-1-infected patients experience an ADR at some point during the course of their treatment thus making ADRs a major public health issue due to their frequency and potential for increased morbidity and mortality [2,47,48]. SMX is a commonly used medication in both HIV-infected and uninfected populations and its metabolism is well known, making it an ideal model compound. The liver is quantitatively the primary site of SMX bioactivation, though metabolism has been shown to occur in other organs including the skin, kidney, lung and cells of the immune system [49,50]. Furthermore, SMX metabolism by dendritic cells enhances their state of activation $[51,52]$. We have previously shown that SMXHA leads to the haptenation of cellular proteins [53] including HIV1 infected Jurkat $\mathrm{T}$ cells and Jurkat $\mathrm{T}$ cells expressing the different deletion forms of Tat (data not shown). Additionally, peripheral blood leukocytes release cytokines on exposure to SMX-HA that are biased to a pro-inflammatory response [54]. We show here that when the cytoplasmic content of Tat is increased, as exemplified by the Tat $\Delta$ GFP and Tat48GFP constructs in the Jurkat $\mathrm{T}$ cell line, this leads to a lower threshold for cell death in the presence of SMX-HA. This leads to our proposed model of ADRs in HIV-1 patients in which the metabolism of SMX leads to the formation of SMX-HA in T cells and other cell types. The death of these haptenated cells would lead to the presentation of SMX-haptenated antigens, activation of dendritic cells and an immune response manifesting clinically as an ADR to SMX. The exact cell death pathway involved in the development of a primary immune response to SMX still needs to be defined as there is past evidence of both apoptotic and necrotic cell death $[8,52]$. Our data also suggests that in order to fully understand the basis of increased ADRs in the HIV-1 population, greater attention to HIV-1 Tat sequence variants and their impact on disease management may be required. This would be akin to the current situation in many jurisdictions where pharmacogenomic screening to 
Citation: Adeyanju K, Dekaban GA, Rieder MJ (2016) Cytoplasmic Distribution of HIV-1 Tat Sensitizes Jurkat T cells to SulphamethoxazoleHydroxylamine Induced Toxicity. HIV Curr Res 1: 105.

Page 11 of 12

identify individuals at high-risk for an ADR is recommended before the initiation of therapy with certain antiretrovirals [55,56]. Advances in our understanding of the mechanisms behind an ADR in HIV-1infected individuals will help the development of screening strategies that may permit the avoidance of ADRs, the delivery of more effective treatment and reduced hospitalizations.

\section{Authors Contributions}

Dr. Adeyanju was involved in the experimental design, carried out the experiments, analyzed the data and wrote the manuscript. Drs. Dekaban and Rieder conceived of the study, participated in the experimental design and helped revise the manuscript. All authors read and approved the final manuscript.

\section{Acknowledgements}

The authors would like to thank Wilfrid Chan and Lindsey Chow for assistance in carrying out some of the experiments. KA received a HIV-1/AIDS Research Initiative Doctoral Research Award (Biomedical/Clinical Stream) from the Canadian Institutes of Health Research (CIHR). This work was also supported by a CIHR grant to MJR.

\section{References}

1. Carr A, Tindall B, Penny R, Cooper DA (1993) Patterns of multiple-drug hypersensitivities in HIV-infected patients. AIDS 7: 1532-1533.

2. Rieder MJ (2009) Immune mediation of hypersensitivity adverse drug reactions: implications for therapy. Expert Opin Drug Saf 8:331-343.

3. Lin D, Tucker MJ, Rieder (2006) Increased adverse drug reactions to antimicrobials and anticonvulsants in patients with HIV infection. Ann Pharmacother 40: 1594-1601.

4. Rieder MJ, Krause R, Bird IA, Dekaban GA (1995) Toxicity of sulfonamidereactive metabolites in HIV-infected, HTLV-infected, and noninfected cells. J Acquir Immune Defic Syndr Hum Retrovirol 8: 134-140.

5. Naisbitt DJ, Farrell J, Gordon SF, Maggs JL, Burkhart C, et al. (2002) Covalent binding of the nitroso metabolite of sulfamethoxazole leads to toxicity and major histocompatibility complex-restricted antigen presentation. Mol Pharmacol 62: 628-637.

6. Rieder MJ, Uetrecht J, Shear NH, Cannon M, Miller M, et al. (1989) Diagnosis of sulfonamide hypersensitivity reactions by in-vitro "rechallenge" with hydroxylamine metabolites. Ann Intern Med 110: 286-289.

7. Carr A, Tindall, Penny R, Cooper DA (1993) In vitro cytotoxicity as a marker of hypersensitivity to sulphamethoxazole in patients with HIV. Clin Exp Immunol 94: 21-25.

8. Arp J, Rieder MJ, Urquhart B, Freeman D, Tucker MJ, et al. (2005) Hypersensitivity of HIV-1-infected cells to reactive sulfonamide metabolites correlated to expression of the HIV-1 viral protein tat. The Journal of pharmacology and experimental therapeutics 314: 1218-1225.

9. Romani B, Engelbrecht S, Glashoff RH (2010) Functions of Tat: the versatile protein of human immunodeficiency virus type 1. J Gen Virol 91: 1-12.

10. Campbell GR, Loret EP (2009) What does the structure-function relationship of the HIV-1 Tat protein teach us about developing an AIDS vaccine? Retrovirology 6: 50.

11. Campbell GR, Watkins JD, Esquieu D, Pasquier E, Loret EP, et al. (2005) The C terminus of HIV-1 Tat modulates the extent of CD178-mediated apoptosis of T cells. J Biol Chem 280: 38376-38382.

12. Gulow K, Kaminski M, Darvas K, Suss D, Krammer PH (2005) HIV-1 transactivator of transcription substitutes for oxidative signaling in activation-induced T cell death. J Immunol 174: 5249-5260.

13. Johri MK, Mishra R, Chhatbar C, Unni SK, Singh SK (2011) Tits and bits of HIV Tat protein. Expert Opin Biol Ther 11: 269-283.

14. Derse D, Carvalho M, Carroll R, Peterlin BM (1991) A minimal lentivirus Tat. J Virol 65: 7012-7015.

15. Carroll R, Martarano L, Derse D (1991) Identification of lentivirus tat functional domains through generation of equine infectious anemia virus/human immunodeficiency virus type 1 tat gene chimeras. J Virol 65: 3460-3467.

16. Huigen MC, Kamp W, Nottet HS (2004) Multiple effects of HIV-1 trans-activator protein on the pathogenesis of HIV-1 infection. Eur J Clin Invest 34: 57-66.

17. Alimonti JB, Ball TB, Fowke KR (2003) Mechanisms of CD4+ T lymphocyte cell death in human immunodeficiency virus infection and AIDS. J Gen Virol 84: 1649-1661.

18. Minami R, Yamamoto M, Takahama S, Miyamura T, Watanabe H, et al. (2006) RCAS1 induced by HIV-1-Tat is involved in the apoptosis of HIV-1 infected and uninfected CD4+ T cells. Cell Immunol 243: 41-47.

19. Dabrowska A, Kim N, Aldovini A (2008) Tat-induced FOXO3a is a key mediator of apoptosis in HIV-1-infected human CD4+ T lymphocytes. J Immunol 181 8460-8477.

20. Kim N, Kukkonen S, Gupta S, Aldovini A (2010) Association of Tat with promoters of PTEN and PP2A subunits is key to transcriptional activation of apoptotic pathways in HIV-1-infected CD4+ T cells. PLoS Pathog 6: e1001103.

21. Adeyanju K, Krizova A, Gilbert PA, Dekaban GA, Rieder M (2009) HIV-1 Tat potentiates cell toxicity in a $T$ cell model for sulphamethoxazole-induced adverse drug reactions. Virus Genes 38: 372-382.

22. Chen D, Wang M, Zhou S, Zhou Q (2002) HIV-1 Tat targets microtubules to induce apoptosis, a process promoted by the pro-apoptotic $\mathrm{Bcl}-2$ relative $\mathrm{Bim}$. EMBO J 21: 6801-6810.

23. Wu RF, Gu Y, Xu YC, Mitola S, Bussolino F, et al. (2004) Human immunodeficiency virus type 1 Tat regulates endothelial cell actin cytoskeletal dynamics through PAK1 activation and oxidant production. Journal of virology 78: 779-789.

24. Wong ML, Medrano JF (2005) Real-time PCR for mRNA quantitation. Biotechniques 39: 75-85.

25. Mosmann T (1983) Rapid colorimetric assay for cellular growth and survival application to proliferation and cytotoxicity assays. J Immunol Methods 65: 5563.

26. Del Gaizo V, Payne RM (2003) A novel TAT-mitochondrial signal sequence fusion protein is processed, stays in mitochondria, and crosses the placenta. Mol Ther 7: 720-730.

27. Bolte S, Cordelieres FP (2006) A guided tour into subcellular colocalization analysis in light microscopy. J Microsc 224: 213-232.

28. Matarrese P, Malorni W (2005) Human immunodeficiency virus (HIV-1)-1 proteins and cytoskeleton: partners in viral life and host cell death. Cell Death Differ 12 Suppl 1: 932-941.

29. de Mareuil J, Carre M, Barbier P, Campbell GR, Lancelot S, et al. (2005) HIV-1 Tat protein enhances microtubule polymerization. Retrovirology 2: 5 .

30. Epie N, Ammosova T, Sapir T, Voloshin Y, Lane WS, et al. (2005) HIV-1 Tat interacts with LIS1 protein. Retrovirology 2: 6.

31. Truant R, Cullen BR (1999) The arginine-rich domains present in human immunodeficiency virus type 1 Tat and Rev function as direct importin betadependent nuclear localization signals. Mol Cell Biol 19: 1210-1217.

32. Fittipaldi A, Giacca M (2005) Transcellular protein transduction using the Tat protein of HIV-1. Adv Drug Deliv Rev 57: 597-608.

33. Wei P, Garber ME, Fang SM, Fischer WH, Jones KA (1998) A novel CDK9 associated C-type cyclin interacts directly with HIV-1 Tat and mediates its highaffinity, loop-specific binding to TAR RNA. Cell 92: 451-462.

34. Bres V, Tagami H, Peloponese JM, Loret E, Jeang KT, et al. (2002) Differential acetylation of Tat coordinates its interaction with the co-activators cyclin T1 and PCAF. EMBO J 21: 6811-6819.

35. Kiernan RE, Vanhulle C, Schiltz L, Adam E, Xiao H, et al. (1999) HIV-1 tat transcriptional activity is regulated by acetylation. EMBO J 18: 6106-6118.

36. Haga N, Fujita N, Tsuruo T (2003) Mitochondrial aggregation precedes cytochrome $\mathrm{c}$ release from mitochondria during apoptosis. Oncogene 22: 55795585 .

37. Peloponese JM, Collette Y, Gregoire C, Bailly C, Campese D, et al. (1999) Full peptide synthesis, purification, and characterization of six Tat variants Differences observed between HIV-1 isolates from Africa and other continents. J Biol Chem 274: 11473-11478.

38. Aksenov MY, Aksenova MV, Nath A, Ray PD, Mactutus CF, et al. (2006) Cocaine-mediated enhancement of Tat toxicity in rat hippocampal cell cultures: the role of oxidative stress and D1 dopamine receptor. Neurotoxicology 27 217-228. 
Citation: Adeyanju K, Dekaban GA, Rieder MJ (2016) Cytoplasmic Distribution of HIV-1 Tat Sensitizes Jurkat T cells to SulphamethoxazoleHydroxylamine Induced Toxicity. HIV Curr Res 1: 105.

39. Song HY, Ryu J, Ju SM, Park LJ, Lee JA, et al. (2007) Extracellular HIV-1 Tat enhances monocyte adhesion by up-regulation of ICAM-1 and VCAM-1 gene expression via ROS-dependent NF-kappaB activation in astrocytes. Exp Mol Med 39: 27-37.

40. Liu K, Chi DS, Li C, Hall HK, Milhorn DM, et al. (2005) HIV-1 Tat proteininduced VCAM-1 expression in human pulmonary artery endothelial cells and its signaling. Am J Physiol Lung Cell Mol Physiol 289: L252-260.

41. Coiras M, Camafeita E, Urena T, Lopez JA, Caballero F, et al. (2006) Modifications in the human T cell proteome induced by intracellular HIV-1 Tat protein expression. Proteomics 6 Suppl 1: S63-73.

42. Lopez-Huertas MR, Callejas S, Abia D, Mateos E, Dopazo A, et al. (2010) Modifications in host cell cytoskeleton structure and function mediated by intracellular HIV-1 Tat protein are greatly dependent on the second coding exon. Nucleic Acids Res 38: 3287-3307.

43. Liu L, Xie R, Yang C, McKeehan WL (2009) Dual function microtubule- and mitochondria-associated proteins mediate mitotic cell death. Cell Oncol 31: 393-405.

44. Parness J, Horwitz SB (1981) Taxol binds to polymerized tubulin in vitro. J Cell Biol 91: 479-487

45. Liu L, Vo A, Liu G, McKeehan WL (2005) Distinct structural domains within C19ORF5 support association with stabilized microtubules and mitochondrial aggregation and genome destruction. Cancer Res 65: 4191-4201.

46. Lazarou J, Pomeranz BH, Corey PN (1998) Incidence of adverse drug reactions in hospitalized patients: a meta-analysis of prospective studies. JAMA 279: 1200-1205.

47. Borras-Blasco J, Navarro-Ruiz A, Borras C, Castera E (2008) Adverse cutaneous reactions associated with the newest antiretroviral drugs in patients with human immunodeficiency virus infection. J Antimicrob Chemother 62: 879-888.

48. Manzardo C, Zaccarelli M, Aguero F, Antinori A, Miro JM (2007) Optimal timing and best antiretroviral regimen in treatment-naive HIV-1-infected individuals with advanced disease. J Acquir Immune Defic Syndr 46 Suppl 1: S9-18.

49. Cribb AE, Miller M, Tesoro A, Spielberg SP (1990) Peroxidase-dependent oxidation of sulfonamides by monocytes and neutrophils from humans and dogs. Mol Pharmacol 38: 744-751.

50. Vyas PM, Roychowdhury S, Koukouritaki SB, Hines RN, Krueger SK et al. (2006) Enzyme-mediated protein haptenation of dapsone and sulfamethoxazole in human keratinocytes: II. Expression and role of flavincontaining monooxygenases and peroxidases. J Pharmacol Exp Ther 319: 497-505.

51. Sanderson JP, Naisbitt DJ, Farrell J, Ashby CA, Tucker MJ, et al. (2007) Sulfamethoxazole and its metabolite nitroso sulfamethoxazole stimulate dendritic cell costimulatory signaling. J Immunol 178: 5533-5542.

52. Elsheikh A, Lavergne SN, Castrejon JL, Farrell J, Wang H, et al. (2010) Drug antigenicity, immunogenicity, and costimulatory signaling: evidence for formation of a functional antigen through immune cell metabolism. J Immuno 185: $6448-6460$

53. Manchanda T, Hess D, Dale L, Ferguson SG, Rieder MJ (2002) Haptenation of sulfonamide reactive metabolites to cellular proteins. Mol Pharmacol 62: 10111026.

54. Hess DA, O'Leary EF, Lee JT, Almawi WY, Madrenas J, et al. (2001) Inhibition of cytokine production and interference in IL-2 receptor-mediated Jak-Stat signaling by the hydroxylamine metabolite of sulfamethoxazole. Faseb $\mathrm{J} 15$ : 1855-1857.

55. Haas DW, Tarr PE (2015) Perspectives on pharmacogenomics of antiretrovira medications and HIV-1-associated comorbidities. Curr Opin HIV AIDS 10: 116122.

56. Martin MA, Kroetz DL (2013) Abacavir pharmacogenetics--from initial reports to standard of care. Pharmacotherapy 33: 765-775 